French Cabinet, gave to historians new and valuable material in his six quarto volumes on the ancient Greek alchemists, and the writers of the middle ages, but the most carefully written general history of recent date is that of Ernst von Meyer (Leipzig, 1889), and that of $A$. von Ladenburg, which is now under review in its English dress.

This is not a history of chemists and their labors but a philosophical study of the growth of the science since the period when Lavoisier placed it on a firm basis; the author magnifies the part played by Lavoisier, shows the origin of the false claim made for Wenzel, does justice to Richter who introduced the term stoichiometry, points out that the atomic weights of Dalton were rather arbitrarily ascertained, though he says nothing to belittle his genius.

The fact that the matter is presented in lecture form has its advantages, and assists the author in his attempt to follow the development of our present ideas from those that were formerly current; while written concisely, the student can pursue given topics more thoroughly by referring to the many treatises and articles named in foot-notes.

As thirty years elapsed between the first publication of the work in German and the appearance of this English translation, Dr.von Ladenburg has added another chapter, bringing the history down to date. In this he does justice to the labors of Gibbs, Ostwald, and van' $t$ Hoff in developing the physical aspect of chemistry, the ionization theory, and the advance made in electrochemistry. Dr. von Ladenburg's lectures are altogether the strongest writings on the development of the recent aspects of chemistry, and are recommended to readers seeking an adequate presentation of this subject.

The English translation is admirable; we notice, however, a few blemishes in proof-reading; e.g., "Mon-atshefte," and I77I for the date of Priestley's discovery of oxygen. The indexes to names of persons and to subjects are in distinct alphabets, an arrangement the advantages of which are not evident.

\title{
HENRY CARRINGTON BOLTON.
}

Experiments on Losses in Cooking Meats. By H. S. Grindiey. Bulletin No. 102, U. S. Department of Agriculture, Office of Experiment Stations. Washington: Government Printing Office. 64 pages.

This pamphlet gives the results of investigations carried out in 
the laboratories of the University of Illinois in the years I898$\mathrm{r} 900$, and is one of a series of similar publications sent out from the Office of Experiment Stations. Many of these publications have to do with the broad question of the practical nutrition of man and in this interesting bulletin the results of about twevtyfive complete experiments on the losses resulting in cooking meats in different ways are detailed. The methods of analysis employed are also given when necessary, which adds to the value of the pampllet for those engaged in similar researches.

J. H. LONG.

The Practical, Methods of Organic Chemistry. By Ludvig GatterMANN, Ph.D. Translated by Wili.TAM B. SchobER, Ph.D. Authorized translation. The second American from the fourti German edition. New York: The Macmillan Co. Igor, xv $359 \mathrm{pp}$.

This book is so well known in the original that the second English edition translated from the fourth German edition needs no special introduction. The work has served its purpose so admirably that it is already well known to all workers in the field of organic chemistry. The translation is excellent, and as was stated in the preface to the first English edition it "is intended for those students of chemistry who have not yet become sufficiently familiar with scientific German to be able to read it accurately without constant reference to a dictionary." In the present edition a number of new illustrations have been added, and in many cases the laboratory directions have been improved. In that part of the book dealing with preparations, methods for the preparation of the following substances have been added: glycol, dimethylcyclohexanone, $s$-xylenol, phenylhydroxylamine, nitrosobenzene, $p$-tolyl aldehyde (Gattermann-Koch synthesis), salicylic aldehyde (Reimer and Tiemann's oxyaldehyde synthesis), cuprous chloride, the decomposition of inactive mandelic acid into its active constituents, and a zinc dust determination.

H. FAY.

LOGarithms of Numbers aNd CheMical Factors. By CHarles R. SANGER. Publication Office of Harvard University, IgoI.

This publication in the form of a large card, is essentially a fifth edition of the well-known table of Wolcott Gibbs. It is based on the table of atomic weights which was compiled by Richards in April, IgoI, and covers thirty-seven elements. The logarithms are those which are required for the reduction of 